\title{
¿Qué es un cuerpo seguro? El feto entre política y comunicación
}

\author{
What is a safe body? \\ The foetus between politics and communication
}

\section{Cristian Alexis Cabello Valenzuela}

Estudiante Magíster Universidad de Chile cristiansereno@gmail.com

\begin{abstract}
SÍNTESIS
En mayo de 2011 y durante solo tres días el gobierno de Chile suprimió el uso de químicos lacrimógenos para reprimir manifestaciones por sus posibles efectos abortivos. A partir de este "momento político"-que puso en duda a una política oficial-el presente ensayo realiza un análisis de los modos de enunciación comunicacional que representaron al feto en política, una figura que develó su fuerza como significado relacionado con la vida. La discusión del feto desde la comunicación-más allá de visiones a favor o en contra del aborto-revela la importancia de los discursos técnico-científicos para la política actual y la fragmentación tecnologizada y visual del cuerpo, reconfiguraciones de los modos de comprender el cuerpo en un contexto mediatizado.
\end{abstract}

\begin{abstract}
In May of 2011 and for only three days the government of Chile eliminated the use of chemicals to suppress protests because of its possible abortifacient effects. From this "political moment" -questioned official policy-this essay is an analysis of modes of enunciation fetus representing communication in politics, a figure that revealed strength as related to life meaning. The discussion of the fetus from the communication -past visions in favor against abortion-reveals the importance of technical and scientific discourse to the current policy and technologized and visual fragmentation of the body, reconfiguration of the ways to understand the body in the mediated context.
\end{abstract}

Palabras claves: Comunicación, biopolítica, feto, ciencia, visualidad.

Keywords: Communication, biopolitics, fetus, science, visual. 
El feto aparece de modo polémico en el escenario público mediático, una biología política que aparece como cualquier otra partícula ciudadana. Un no-sujeto ${ }^{1}$ que protagoniza sin voz propia tensiones y conflictos en "la política" y su sistema de poder oficial. Sorprendente es cómo un grupo de células indiferenciadas, el momento original de lo denominado vida, se hace parte y circulación de posiciones transcendentales para la política. Esta organicidad de células cubiertas y escondidas en úteros (e invisibles para la mirada humana) aparece constantemente en el territorio de la política, su presencia es siempre polémica ya que constituye de por sí un conflicto moral y político. ¿Pero cómo se hacen visibles este conjunto de células? El presente texto busca reconocer cómo vemos y de qué modo es la representación política del feto en el espacio comunicacional de la política, que desde ya señala -al incluir al feto en su campo- una barrida a delimitaciones binarias de la política oficial, haciendo suya las ficciones biológicas de un feto, otorgándole una presencia más que humana y con poder a estas células comprendidas como la "vida". Se trata de un análisis desde la extrañeza que significa un feto en la política y desde la profundidad con que los discursos biológicos se entrelazan para descentrar la política.

Fijar la mirada en el feto es un modo de desorientar la mirada de lo común, de posiciones ya definidas o discusiones consideradas ya acabadas. Por lo tanto el presente texto no busca reedificar una identidad o representación de la política, sino atreverse a pensar eso que el feminismo más ortodoxo no se ha atrevido a discutir por considerarlo "biológico" o "esencialista". Las discusiones sobre el aborto insisten en legitimar solo la existencia de la mujer, negando la producción simbólica de una figura como el feto, ya que "la sociedad debe considerar, en primer término, la condición del sujeto mujer" (Casas, 2009). Más que buscar mejorar la representación de las mujeres en política o "corregir la subrepresentación de las mujeres en política" (Castillo, 2011, 87), más que confiar en otra naturaleza simbólica es primordial poner en disputa y conflicto conceptos ya naturalizados y hegemónicos en el espacio público y político de la comunicación ${ }^{2}$. 


\section{Un dolor sin cuerpo}

Así sucedió con la paradójica "acción política” donde el gobierno de Sebastián Piñera decidió paralizar el uso de bombas lacrimógenas (utilizadas como violencia estatal o represión del Estado contra cuerpos de manifestantes para retornar al orden) durante las manifestaciones ciudadanas de carácter ecológico realizadas durante mayo de 2011 en la ciudad de Santiago. La tensión entre ciencia y política -o la intromisión explícita del discurso científico como política- se hizo visible unos días antes cuando Andrei Tchernitchin, experto en Toxicología de la Facultad de Medicina de la Universidad de Chile, afirmó "el potencial efecto abortivo de las bombas lacrimógenas que son usadas por Carabineros para disuadir manifestaciones" ${ }^{\prime 2}$. Las armas del gobierno, que se asoman públicamente no como armas sino como posibilidad de orden y seguridad, paradoja que ya reconoce Esposito al presentar la fuerza y violencia propia de cada ley, donde el derecho convocado para la producción del orden y la seguridad pública no es más que "una violencia a la violencia por el control de la violencia", "un pasaje interno de la violencia: su racionalización" (Esposito, 2005, 46-48). Estas tecnologías de castigo, ya no dañan todo un cuerpo, ya no se da un combate entre dos equipos de modo explícito, se deja de lado la lucha física. Así lo afirmaba el toxicólogo respecto a los efectos del gas CS usado en las lacrimógenas:

"[es] un agente irritante, cuyo efecto dura 30 minutos y produce lagrimeo, visión borrosa, irritación bucal, cefalea, salivación intensa y dificultad para respirar, también puede producir sangramiento de las narices y edema pulmonar (...) [nosotros] propusimos que uno de los efectos que podría producir sería inducir abortos o partos prematuros e Israel confirmó que este componente es abortivo y también puede generar problemas respiratorios graves en la tercera edad y los niños" ${ }^{\prime \prime}$.

Un daño momentáneo, que parecía no importar, ya que era justamente temporal, sin efectos profundos en el cuerpo. Sin embargo, la posibilidad de aborto que presentaría señala un hito que marcaría más allá de lo anecdótico al cuerpo. La política oficial, gubernamental, ya no hace sangrar al enemigo, sino que el daño es químico, menos visible: vía oral, nasal, respiratoria y ocular, el clorobenzilideno 
malononitrilo que contienen estas "armas de la seguridad" asfixia los sentidos, impide ver el horror de la violencia, desorienta los sentidos al frenar la posibilidad de ser el espectador del daño ${ }^{5}$, dificulta respirar con normalidad, convulsiona el cuerpo, pero solo por más de 20 minutos, es decir llegamos a un momento extremo donde la violencia -adueñada por presentismos- se vuelve "temporal". El daño parecía ser focalizado y temporal, sin huellas, su efecto no está dirigido a un sujeto en particular, sino a los órganos y la sistematicidad del cuerpo, no al cuerpo en sí.

Este giro desubjetivizante es radical para comprender los modos de acción de la política actual donde "el cuerpo no está [en la política] o, por lo menos, no es uno. Ni siquiera la guerra moderna toma hoy el cuerpo seriamente (...) [porque] no se trata ya de matar sino de permitir que algunos continúen viviendo" (Braidotti, 2000, 99). Esto lo afirma la teórica feminista Rosi Braidotti en su ensayo Órganos sin cuerpos donde muestra cómo el cuerpo es representado fragmentariamente en el escenario público-político, siendo ahora lo comunicacional biopolítico la producción de imágenes de órganos más deslocalizados, órganos de cualquiera, órganos que son fetiche absoluto y atento del Estado y que permiten restar la traumática y compleja experiencia que significa ejercer la política con individuos. Presenciamos entonces "el ocultamiento del cuerpo físico" (Braidotti, 2000,99) reemplazada por una circulación de los fragmentos, unos zooms que desorientan pero que otorgan la impresión de conocer con más profundidad o una exhibición científica que permite exhibir de modo más real ("3D", "digital") incluso el "interior" del cuerpo. Esta es una transformación radical de una escópica del cuerpo, ya que el daño sería focalizado, más controlado y por lo tanto menos relevante para los sujetos. Son estos istmos corporales los que ya no constituyen simplemente mera superficialidad de la vida cotidiana, sino que esta semiotización es política en tanto neutraliza y controla su relación con una violencia oficial. Se trata de una tecnología incluida en el cuerpo, una tecnología que no es inocencia, sino que está producida y produce ciertos saberes y sentidos sobre la vida. Figuras tan particulares se convierten fundamentales en el "mundo práctico": "chip, gen, semilla, feto, base de datos, bomba, raza, cerebro, ecosistema. (...) Estamos habitados y deshabitadas por estas 
figuras que diseñan universos de conocimiento, práctica y poder" (Haraway, 2004, 28).

Existen múltiples discursos -y divergentes- que desde distintas ciencias y saberes se apropian de fragmentos materiales de los cuerpos: psicología, higiene, ecología, seguridad, moda, tecnologías, política y comunicación son algunas de las "disciplinas" desde donde el cuerpo es retomado como el centro de sus funciones disciplinarias, funciones que por su multiplicidad producen desorientaciones y confusiones en el orden del sujeto. Lo fundamental entonces es que estos fragmentos-órganos-con-vida logran una escenificación pública sobresaliente y protagónica, tanto que ya no luchamos en política por una integración de sujetos políticos, sino que enfrentamos una política que nos hace mirar como su esencia unos "órganos políti$\cos ^{\prime \prime}$. La política ya no requiere de la generalidad de un cuerpo, sino que lucha políticamente por un corazón sano, en contra del cáncer, en apoyo a la reconstrucción de la sonrisa de las mujeres ${ }^{6}$, luchas fragmentarias donde lo central es una parte desubjetivizada de los ciudadanos. Este control hiperdiseccionado en torno a la vida de los sujetos ya lo visualizó Foucault cuando se refería a que la política estaba en el cuerpo o "anatomía política" referente a una microfísica del poder que disciplina las conductas de los cuerpos y que "tiene su intensidad máxima no en la persona del rey, sino en los cuerpos que esas relaciones, precisamente, permiten individualizar" (Foucault, 2002 , 211). Pero es momento de radicalizar y exacerbar la tesis de la disciplina frente a un poder que se olvidó del cuerpo para pasar a sus fragmentos como foco de (des)atención pública.

Es así como el feto ${ }^{7}$ se asoma como un organismo más presentado y presente por una política dedicada e interesada en hacer representaciones públicas de lo biológico como eje moral y ético de su plataforma mediática. De este modo, y frente al temor de producir abortos a partir de las tecnologías de orden público, el Ministerio del Interior y Seguridad Pública del Gobierno de Chile, Ministro Rodrigo Hinzpeter, decidió suspender el uso de bombas lacrimógenas en contra de los manifestantes que recorrieron de modo masivo y excepcional las avenidas del centro de Santiago:

"Siendo la protección de nuestros compatriotas el principal objetivo de nuestro Gobierno, nos parece que es razonable suspender el 
uso de esos gases lacrimógenos hasta que nuevos informes médicos nos permitan disipar más allá de cualquier duda la procedencia del empleo de estos gases para enfrentar situaciones de desorden público"s.

Con esta acción ocurrió una fisura, una puesta en duda desde lo biológico que afectó la rigurosidad de la seguridad del Estado, a través de una extraña decisión política de carácter pacífica que se extendió como medida solo por 3 días, es decir como una excepción, una duda del Estado.

Una naturaleza que podía morir estaba en tensión tanto en los terrenos geográficos como corporales, ambos territorios en disputa donde lo natural buscaba permanecer intacto9. Mientras se posicionaban a favor de la naturaleza, en contra de unas tecnologías transnacionales que podrían "inundar lo natural" del sur de Chile, las tecnologías químicas de represión intoxicaban el deseo de la protesta. La bioviolencia de los químicos se introducía en los organismos y ahí, en la posibilidad médica, aparece el feto como otro tipo de política de lo natural. El feto que fue posicionado como una "vidavíctima", como una biología vulnerada, un modo de defensa de la vida natural, pero por sobre todo como el modo principal en que el Estado protege a sus ciudadanos. Si bien no se menciona de parte de la oficialidad la cuestión del feto de modo explícito, se asume como una negación afirmativa que produce un actuar en torno a la protección y precaución de la política. Es el feto la única vida, la vida más pura, que interesa a la política mantener viva. Paradojalmente, sin ni siquiera ser lema de los manifestantes, esta politización biológica esencialista del feto se vuelve el principal (e inesperado) gesto pacífico y no-violento de una "política fetal" que justamente hace (in) visible su violencia gracias a las sobredosis simbólico-mediáticas de la protección ciudadana: quien producía la seguridad y protegía a sus ciudadanos, ahora puede que realice un daño.

Sin embargo, es también paradojal que, si bien sabemos que las herramientas de control y orden público como las lacrimógenas producen un daño -invisible en tanto no se hace público- o ejercen violencia sobre los cuerpos que se manifiestan, contrariamente es el daño que afectaría al feto el que logra mayor realce y protagonismo en la escena política, es esa vida, eso que no se nombra pero que 
puede estar ahí en los cuerpos de quienes protestan. Es esta "vida" la que sobrepasa y se realza por sobre miles de cuerpos que son reprimidos en el espacio público. ¿Esta sobreexposición espectacular del feto (o su posibilidad) se deberá justamente a que no hay precisión científica sobre su existencia y por tanto es este dolor sin cuerpo el que se considera más positivo y protagónico para hacerse mostrar en la política, en detrimento de ese otro daño que afecta como un ya sabemos a los manifestantes de las calles?

\section{El poder de lo innombrable}

La característica de la aparición del feto en el espacio públicocomunicacional es justamente la dificultad de nombrarlo. Se crean y reproducen estrategias de la discursividad política precisamente para no nombrar lo innombrable que lo constituye: la posibilidad del feto. El feto nunca aparece en política sino solo a través de sus contornos, sus merodeos que no demuestran sino el miedo de la política frente a la dificultad y el cuidado de nombrar a una "política fetal".

Una dificultad significa abordar la discursividad política del feto a través de sus representaciones. Analizando la imagen del feto el biólogo Jorge Díaz se pregunta “¿cómo mirar estas ecografías de fetos reproducidas por una tecnología audiovisual en cuyas imágenes se conectan debates tan polémicos y necesarios como el derecho al aborto y el estatuto de lo "humano"?" (Díaz, 2011). Ante la polemicidad del feto como política no podemos reducir su significado a un valor naturalizado ni menos a lo estático de una cosificación representacional. La significación política no se comporta solo como información, espectáculo, referencia, "pura exhibición, alusión o tratamiento, sino que ella estaría alojada en su propia producción y circulación discursiva (...) constituyendo a la propia televisión como un agente discursivo y un dispositivo de enunciación política" (Arancibia, 2006, 89). Es el cómo se producen las articulaciones del feto -y no qué es el feto- el cuestionamiento que dirige la presente investigación, comprendiendo esa anatomía de la comunicación, sus articulaciones, ese "cuerpo de las imágenes" entendido como "una problemática sobre las condiciones enunciativas no lingüísticas de la mediatización" (Verón, 2001, 110). Esta mirada crítica sobre la comunicación 
política impide caer en los pantanos de la ética y la moral respecto al cruce entre política y feto, pero además coopera como metodología para comprender esa desaparición de la representación como contenido en la mediatización del feto en el caso analizado en Chile.

Así, por ejemplo, los discursos del Ministro del Interior manifestaron -entre la seriedad política y el manto de desconocimiento sobre el mismo tema- lo innombrable del feto como definición de su misma política fetal:

\begin{abstract}
"con el objeto de dar espacio para que esta legítima polémica se disipe [¿se refiere a la polémica por la posibilidad de abortar eso que llamamos vida, embrión, feto?] y todos los chilenos podamos tener la tranquilidad de que estamos frente a elementos que pueden usarse en situaciones de desorden público o eventualmente nueva información científica nos allegue a conclusiones distintas [¿distintas respecto a la posibilidad de que las lacrimógenas dañen al feto?], hemos resuelto que estos gases lacrimógenos no sean utilizados por Carabineros de Chile"10.
\end{abstract}

¿No serán utilizados estos gases justamente para cuidar la vida de posibles embriones de padres revolucionarios? ¿Qué es lo que la política no desea nombrar, sino solo merodear y aplicar bajo conceptos técnicos como lo demuestra el discurso del ministro (donde a pesar de lo técnico-científico no hay nada exacto)? El feto nunca aparecerá en política sino como fragmento, o también como lo no-dicho, lo liminal del discurso. Sin embargo el feto aparece, está presente, es una presencia sin cuerpo mediatizado que genera y produce la activación de una política discursiva de la precaución y el cuidado, promueve la revisión y examinación atenta y permanente.

La paradoja es: ¿cómo representamos lo que se mantiene desaparecido para el mirar? Al parecer la política ya no requiere de lo visible sino de lo visual:

"la lógica despiadada y fundamentalmente mercenaria de la representación tiene prioridad sobre lo representado, esta tendencia marca el triunfo de la imagen, del objeto representado, de lo visible en la medida en que se hace visual: es decir, un objeto de consumo escópico. Hiperrepresentado de manera hiperrealista, este objeto permanece profundamente ausente (como "el cuerpo", la "mujer", "lo femenino", etc.)" (Braidotti, 2000, 98) 
El feto no existe sino es en su exceso de visualidad, en su saturación de significados, en su visualidad esparcida que no lo restringe a ningún lugar. El feto como embarazo puede estar en cualquier mujer manifestante, no parece ser puntualmente de un lugar específico. El feto no está en ninguna parte precisa, sino que en todo lugar puede aparecer como amenaza. Su hiperrepresentación produce una alarma pública, ya que siempre conlleva peligro de muerte. A una embarazada debemos dar el asiento, porque si no hay peligro de pérdida. Cuando el gobierno justamente se preocupa de esta "vida" -no es un sujeto específico el feto-, protege al feto desde el Estado más que desde la protección de una vida física y "real", más que el cuidado por un futuro ciudadano; se establecen los límites y fronteras de lo posible para una comunidad política: "Cuando a uno le plantean que puede producir aborto, lo primero que hace es suspenderlo, obviamente no estoy dispuesto a que ningún chileno corra riesgos, (pero) los estudios los tengo que hacer con rapidez, porque estoy privando a Carabineros de un elemento básico para el orden público"111, señaló el jefe de Gabinete.

Hay algo innombrable ubicado entre el feto y el no-feto, entre la vida y la muerte, hay "algo" al "final" del discurso de la política que supone la posibilidad del feto muerto. La particularidad aquí es el hecho de no nombrar al feto: situarlo como un imposible, un idealismo o meramente una notoriedad de lo extraño en su advenimiento. Esta estrategia discursiva -excesivamente precavida de la políticaseñala lo innombrable del feto en la política, no como un imposible, una prohibición por abyecto o una falta de respeto, sino como un terreno árido y complejo. El no tener nombre, el no tener lugar en el discurso, no propone al feto como un "desamparado" de la política, sino que justamente su deslocalización lo hace una posible presencia en todas partes. Los merodeos del discurso político no hacen sino deslocalizar al feto de todo lugar: despojándolo de las mujeres, distanciándolo de la violencia de la política, superando unitariamente cualquier diferencia o toma de palabra política ciudadana respecto al feto y, por sobre todo, superponiéndolo encima del daño/dolor de quienes "realmente" se manifiestan, es decir volviendo una representación -gracias a su ausencia de especificidad-omnipresente en todo cuerpo de la política. Una preocupación imprecisa que debido a su ausencia de fronteras pareciera estar en todas partes, pero, por 
lo tanto, también en "ninguna parte": lo "ilimitado de "todos los lugares", crea un vasto mundo sin fronteras que llama a deambular por todas sus redes sin que haya tope al deseo nómade de la librecirculación" (Richard, 2010:424). Episteme propia de una política sobre entusiasmada con los beneficios "liberadores" de un mundo "siempre conectado". Sin embargo, Nelly Richard advierte respecto a esta política sin fronteras que "las vinculaciones y las interconexiones entre fronteras dependen siempre del agenciamiento de un diagrama, entendido éste como la organización espacial de un mapa de desplazamientos y de emplazamientos tácticos de las localizaciones" (Richard, 2010, 425).

Así se insiste en la difusión comunicacional del conflicto en un uso técnico discursivo que distancia cualquier localización y pone en un margen orbitante al feto:

“El jefe de gabinete dijo que los resultados de los estudios recibidos señalan que los gases lacrimógenos, 'en las concentraciones empleadas, que es de 0,4 miligramos por metro cúbico, no tienen efectos', aludiendo al elemento CS que componen los cartuchos y granadas del personal policial" ${ }^{\prime 2}$.

El lugar privilegiado respecto a la pertenencia del feto es, en nuestro caso, una política oficial que atribuye la decisión y el sentido del feto aparentando no-pertenencia. En el discurso de la política el feto no tiene ningún lugar aparente y esta no es más que una estrategia de una política que no toma ningún riesgo sobre sus cuerpos, que despoja a los cuerpos de las mujeres como lugar legítimo para hacer política, que construye una política más allá de las posiciones/localizaciones precisamente para presentar representaciones políticas dibujadas como una totalidad de lo unitario. La situación política de que ya no existe ningún lugar definido ni confiable en la política es propio de lo que Chantal Mouffe sentenció de modo crítico como "postpolítica"13, ya que permite en su disolución de las fronteras y posiciones políticas, en su imaginación de que la política adversarial ya fue y la peligrosa representación comunicacional (o percepción) de que no existen diferencias entre quienes se enfrentan en la política. Justamente lo que hace esta lógica "postpolítica" es pensar que es mejor y más bueno para la política la eliminación del conflicto adversarial de la política. Para Mouffe precisamente el 
discurso de la postpolítica es propio de relatos de derecha (aunque no exclusiva, ya que se extiende como uso propio de los populismos) y su incursión "debilita la oposición izquierda/derecha por un nuevo tipo de nosotros/ellos construido en torno a una oposición entre 'el pueblo' y 'el establishment'” (Mouffe, 2007, 76). En una política liberal ahora el feto es ese significado absoluto que representa al pueblo, ese pueblo populista que identifica y une a todos en la política más allá de las diferencias y posiciones. Esta es la gran estrategia discursiva de esta política de derecha. Se trata del advenimiento de una política de derecha que eleva como identificación posible conceptos "arcaicos", como "pueblo" o en nuestro caso "feto", el nuevo modo más técnico-biológico de decir "pueblo".

\section{¿Qué es un cuerpo seguro?}

El feto es una sobrerepresentación de una ausencia que está en la posibilidad de todos los cuerpos ("todo sujeto puede ser padre gracias a las tecnologías"), lo relevante es reconocer cómo su ausencia se hace "presente" a través de representaciones. Sin duda el discurso biológico juega un rol fundamental para sustentar su existencia (y para quitar el miedo posible que constituye a una figura como el feto), ya que el cruce entre las lógicas biotecnológicas y la política producen la existencia de la probabilidad o, más aún, la posibilidad de una vida, pero el feto acá aparecería solo como una posibilidad médica, como un supuesto que penetra en la protesta. Foucault ya señalaba como "lo biológico se refleja en lo político" (Foucault, 2000, 172) porque la experiencia política se biologiza en tanto nos interesamos en las probabilidades técnicas, se trata de "tener la certeza de que hemos estado trabajando con material debidamente certificado" 14 , se trata de un cuerpo-experiencia-máquina preocupada e interesado en asegurar en su política la posibilidad de "tener un cuerpo, condiciones de existencia, probabilidades de vida, salud individual y colectiva" (Foucault, 2000, 172).

Ya no importa qué vida, ni cómo se debe vivir esa vida, sino simplemente que sea una vida (incluyendo lo metafórico y cristiano del concepto), independiente de los límites y ordenamientos que hagan (in)vivible la vida. Los relatos biológicos permiten dar vida o dar prueba que una experiencia es más cierta y verdadera. De este modo 
es menos cierta la lucha de quienes se manifiestan en contra de la destrucción de la naturaleza (por "ideológicos" o "soñadores") y es más comprobable lo fundamentado a través de discursos y técnicas biomédicos.

Pero también podemos observar el problema desde otra arista que disloca modos formales de comprender la política: quizás la lucha de los ecologistas o los ciudadanos a favor de una naturaleza es demasiado clara, posicional y transparente, tanto así que "la política" ya sabe qué decir y hasta qué punto debe tratar con estas manifestaciones. No hay nada para imaginar -se trata de un actuar político más preestablecido, que no sorprende ni en su uso del espacio público, ni en sus demandas, porque no tiene nada inesperado en su modo de representación-; y, por otro lado, está la posibilidad desconocida de que algún feto pierda su vida entre esa masa incontable de manifestantes afectados por las bombas lacrimógenas. Quizás esta imprecisa y desconocida población -desconocida en tanto cuerpos, tamaños y cantidades de úteros, pero reconocidos en torno a sus afirmaciones y pensamientos políticos- sea aún más peligrosa para una política gubernamental justamente porque en ella no hay ningún grado de precisión o control de los cuerpos. Pero más aún, no hay a "ciencia cierta" conocimiento sobre estos cuerpos. "Lo que amenaza al derecho [la ley, la política,] no es la violencia [de quienes protestan], sino su 'afuera'. El hecho de que exista un fuera-del-derecho' (Esposito, 2005, 47). Por lo tanto la política gubernamental actuará produciendo ciencia sobre estos cuerpos en protesta, un despliegue de conocimientos biomédicos para restar y quitar lo desconocido de esta otra política que se hace en los cuerpos y en la vida, ya no en las afirmaciones políticas ni en sus peticiones discursivas a los organismos estatales. El Estado resta lo desconocido, quita lo que produce terror en estos cuerpos, generando saberes específicos, permitiendo simplemente que sean conocibles, ya no desde un conocer desde la identidad, sino desde la misma narrativa científica. Siguiendo a Foucault, no estamos frente a un poder que tan solo castiga de modo sangriento y físico a los cuerpos, sino que el poder busca controlar estos cuerpos desde su concepción. Quizás lo más problemático es que el poder no tenga conocimiento "preciso" sobre lo que pueda ocurrir con estos cuerpos y es por esto que busca conocer, pero ese 
conocer significa también dar una forma y establecer los límites a estos cuerpos.

La política no responde a los manifestantes con más violencia o mayores elementos de poder físico, sino que responde "haciendo pruebas", "solicitando estudios", "evaluando", "haciendo consultas", conceptos técnicos que se hacen parte de la política y que neutralizan a la ciudadanía: "el Gobierno realizó los estudios necesarios para determinar que las bombas lacrimógenas que utiliza Carabineros para contrarrestar las manifestaciones no tienen efectos abortivos ni generan problemas para la salud de las personas" ${ }^{15} \mathrm{y}$ "El ministro del Interior dijo que la decisión se tomó tras una serie de estudios e investigaciones que avalan que los elementos químicos que se utilizan no son dañinos para la salud" 16 .

El ejercicio político -que detiene la temporalidad de la misma política- de hacer "pruebas" es una episteme que se despliega como obligación para la intromisión del discurso científico en la política y la delimitación de sus cuerpos. Cabe preguntarse: “¿Por qué hoy en día nuestro sentido de seguridad -estemos o no dispuestos a admitirlo- se basa en la posibilidad de hacer pruebas? Queremos que todo y todos pasen por pruebas" (Ronell, 2009). Sujetos que se ponen a prueba, vidas que están siendo "estudiadas", más que el resultado de la prueba lo cierto es que la seguridad política introduce constantes "pruebas" que de por sí se asumen como verdaderas: la prueba se convierte ahora en el resultado. Este es el canon de seguridad política, ya no tanto evitar el desorden, la barricada, la interrupción de la ciudad, sino dedicarse y esforzarse en demostrar que la seguridad estatal es capaz de investigar y estudiar, para así derribar toda duda. El problema es justamente cuando lo científico se comprende como un significado exclusivamente resolutivo y definitivo, incuestionable, porque poner a prueba significa no tan sólo el cierre y la clausura de su sentido, sino también la posibilidad de la experimentación. La oficialidad pone a prueba para producir una sola verdad, sin embargo la particularidad de la ciencia es que sus resultados producirán más preguntas y dudas. Por otra parte, poner un cuerpo a prueba es también desafiarlo en su integridad, un cuerpo que se pone a prueba será diseccionado fragmentariamente, es así como el feto -en tanto fragmento- encarna una cierta verdad política. La acción de abortar tiene mucho de experimentación, un poner a prueba el cuerpo de la 
mujer. Sin embargo su principal rechazo en política se instituye en aquellos discursos del terror que insisten en representar el aborto como una acción sin política y una acción, por sobretodo, insegura.

Pero ¿qué es un cuerpo seguro? Esta pregunta es fundamental para comprender algo como la relación entre política, comunicación y cuerpo. Es una constante laboriosa de la política y el gobierno el proponer una vida segura, más aún, imponen la norma de que los cuerpos deben estar y sentirse seguros. Que un cuerpo se sienta seguro significa que no reconocerá y evitará demostrar cualquier tipo de daño cerca de él, será un cuerpo distante del conflicto. Un cuerpo seguro es uno que necesita ponerse a prueba para demostrar una positiva condición, una entidad limitada y ordenada con sus respectivas ordenanzas, un cuerpo político seguro es aquel que no posee contactos, ni menos contagios. Esta es la acción de vulnerabilidad contra los cuerpos, el poner a prueba para producir un solo sentido es poner en orden los cuerpos, es la herramienta de fuerza que produce el poder estatal en contra de los cuerpos más extraños, esos cuerpos inseguros.

Es preferible para la política que disponga de cuerpos a-segurados, cuerpos que se sabe solo aparecerán en el espacio público para producir una sola acción: por ejemplo, manifestarse en contra de cierta política. Se trata de un unívoco sentido en su comunicación política, ya no la sutura que produce la posibilidad de perder unas vidas. La política de seguridad, más que dañar los cuerpos, evitar barricadas, golpear y castigarlos, busca principalmente asegurar sus sentidos y movimientos en su espacio público comunicacional, definiendo qué cuerpos son seguros y qué otros no.

Lo dicho anteriormente si bien cuestiona y deconstruye la hipervisualidad del feto en la política-comunicacional, no consiste en un llamado a derribar y quitar la presencia fantasmagórica del feto en política, sino todo lo contrario, pretende dudar de la naturalizada representación del feto que como hecho televisivo puede interesar a "todo el mundo", ya que la política fetal analizada en ese episodio de excepción, que hizo "doblegar" al Estado por tres días, es precisamente un hecho noticioso que Bourdieu denomina "para el gusto de todos (...) hechos que, evidentemente, no deben escandalizar a nadie, en los que no se ventila nada, que no dividen, que crean consenso, que interesan a todo el mundo" (Bourdieu, 2005, 22). Lo peligroso es 
cómo el feto aparece como esa representación que une a todos y que no presenta antagonismos ni conflictos, sino que en cambio se asume como un signo que debe "nacer". ¿Acaso -retomando a Bourdieu de modo radical- deberíamos afirmar que el feto no debe interesarnos a "todos" (en contraposición a ese "gusto de todos" que supone y rige el orden televisual)? Sí, pero esto no significa hacer desaparecer al feto y olvidarnos de su representación público-mediática, sino que el feto debe interesar de modo interesado, a través de posiciones específicas que toman la palabra respecto a este signo, es decir, ejercicios que dan nombres a eso que permanecía callado. Signo ya no unívoco, sino polémico, se trata de dar un nombre al feto a través de las voces y diversas interpretaciones y así no mantenerlo como ese territorio innombrable, que no se deja posicionar. Sin embargo, de inmediato surge la duda por lo dicho, ya que el feto es en su mediatización -a pesar de constituir una unidad-en su dimensión pública es una representación polémica, ya que el feto siempre será eso sensacional y espectacular que define a la televisión según Bourdieu. Lo espectacular del feto, en nuestro caso, es la posibilidad de imaginar esa gran matanza de incontables proyectos de vida que afectaría a los manifestantes, sin embargo nunca la política se atreve a nombrar esa posibilidad de muerte que lo aterra, quizás por el trauma que significa imaginar al Estado como asesino masivo. Pero a pesar de esto la causa de lo espectacular es dejada como impensable por la experiencia mediatizada. Este es el error, esta es la concepción clausurada de una política comunicacional que "muestra algo distinto de lo que tendría que mostrar" (Bourdieu, 2005, 24).

\section{Notas}

1 El concepto de no-sujeto es propio de una reflexión político-teórico contemporánea que describe el desgaste o la inoperancia de la categoría de sujeto para describir no-sujetos que ponen en tensión lo material, real, verídico y testimonial de otras entidades subjetivas. "El no sujeto no es ni siquiera fundamentalmente el otro -toda noción del otro presupone siempre de antemano un uno estable y delimitado" (Moreiras, 2006, 13).

2 Alejandra Castillo ya cuestiona las políticas feministas que buscan más presencia de las mujeres como método principal para subsanar -parafraseándola- la relación fallida entre mujeres y política. Criticando esta política de la visibilidad 
señala que "para que funcione la política de 'mayor reconocimiento, mayor igualdad' es necesario preconcebir una identidad 'mujer' rígida (...) No es novedad que a esta altura del debate que esta identidad esté vinculada a las retóricas del amor y a las políticas del cuidado" (Castillo, 2011, 13).

3 Cooperativa.cl. Experto reafirmó potencial abortivo de las bombas lacrimógenas. 16 de mayo de 2011. (consultado 20 de noviembre) Disponible: http: / / www.cooperativa.cl/ experto-reafirmo-potencial-abortivo-de-las-bombas-lacrimogenas/prontus_nots/2011-05-16/074312.html

4 Cooperativa.cl. Experto reafirmó potencial abortivo de las bombas lacrimógenas. 16 de mayo de 2011. (consultado 20 de noviembre) Disponible: http: / / www.cooperativa.cl/ experto-reafirmo-potencial-abortivo-de-las-bombas-lacrimogenas/prontus_nots/2011-05-16/074312.html

5 Quizás esta imposibilidad de ser el espectador del daño sea el objetivo de la lacrimógena, un efecto a nivel de visualidad, que nos explica por qué no vemos la violencia de estas acciones. Pero es más, el efecto bioquímico y escópico de la lacrimógena rompe la posibilidad de que el sujeto-político se identifique con el espectador y que reconozca la experiencia espectacular de los ejercicios de seguridad protagonizados por el gobierno. El daño químico que no nos deja ver obliga a sentir todo el dolor como absolutamente propio, absolutamente de uno, distante de la comunidad. Agrego aquí la advertencia o la relectura de la condición de espectador de Rancière, ya que reconocerse en el espectáculo "no es [o no debe ser] la ostentación de las imágenes que ocultan realidad", no hay una verdad oculta en esas representaciones de violencia, sino que se trata de comprender lo espectacular y al espectador como "la existencia de la actividad social y de la riqueza social como realidad separada" (Rancière, 2010, 47). Imaginamos entonces un espectador que reconoce la importancia de su marco y relación social en lo visto, más que la psicologización individualista de ese dolor.

6 La campaña "Sonrisa de Mujer", contó con la colaboración de la Fundación PRODEMU, Banco del Estado, el Colegio de Odontólogos, empresas privadas y personas naturales, significó la reposición de piezas dentales en mujeres de escasos recursos con la consiguiente mejora en su autoestima, posibilidades laborales y vida familiar. Esta campaña en sus inicios fue liderada por la Primera Dama de Ricardo Lagos, la señora Luisa Durán.

7 Denominaremos de aquí en adelante como "feto" a una categoría biológica, compuesta por una multitud de células, que pueden variar en su proyección y articulación, una categoría que también significa "vida", "origen", "pureza", "lo intacto" para un cambio político-biologicista, una categoría que además asumimos como siempre polémica en tanto es una representación en disputa por grupos políticos diversos. Esta comprensión del feto se restringe solo a sus valores simbólicos en tanto representación y visualidad política. Sin embargo, la característica principal del feto es su multiplicidad de significados en disputa, lo que lo vuelve un signo difuso, inaprensible en un solo nombre, en una sola voz y mirada de la política.

8 Cooperativa.cl. Hinzpeter anunció la suspensión del uso de gas lacrimógeno. 17 de mayo de 2011 (consultado 20 de noviembre) Disponible: http:/ / www.cooperativa.cl/hinzpeter-anuncio-la-suspension-del-uso-de-gas-lacrimogeno/ prontus_nots/2011-05-17/132449.html 
9 Sobre una interpretación que acusa la arremetida conservadora de una "ideología ecológica" remitirse a Slavoj Žižek en el documental Examined Life: philosophy is in the street de Astra Taylor (2008) donde afirma que la "voz ecológica" se articula como una voz invisible que llama a "no violar un cierto límite invisible", su premisa sería que "el mundo existente es el mejor mundo posible, en el sentido de que es mundo equilibrado perturbado por la arrogancia humana". Esta noción de naturaleza armoniosa pensada por el ecologismo sería la cuestión problemática, más aún si se adueña y transita de un modo biológicoesencialista en las interpretaciones políticas que buscan conservar como la perfección de la vida al feto.

10 Cooperativa.cl. Hinzpeter anunció la suspensión del uso de gas lacrimógeno. 17 de mayo de 2011. (consultado 20 de noviembre) Disponible: http:/ / www.cooperativa.cl / hinzpeter-anuncio-la-suspension-del-uso-de-gas-lacrimogeno / prontus_nots/2011-05-17/132449.html

11 La Nación.cl. Hinzpeter: ISP determinó que bombas lacrimógenas no son abortivas. Sábado 21 de mayo. (consultado 20 de noviembre) Disponible: http:/ / www. lanacion.cl/hinzpeter-isp-determino-que-bombas-lacrimogenas-no-son-abortivas / noticias / 2011-05-21/095607.html

12 La Nación.cl. Hinzpeter repone el uso de gases lacrimógenos de carabineros. 20 de mayo (consultado 6 de diciembre) Disponible: http://www.lanacion. $\mathrm{cl} /$ hinzpeter-repone-el-uso-de-gases-lacrimogenos-de-carabineros / noticias / 2011-05-20/133322.html

13 Postpolítica refiere -de modo sintético- al supuesto compartido de que la política ya no requiere de posiciones claras o que, simplemente, las posiciones de la política (izquierda/derecha) se presentan desgastadas para identificar a la ciudadanía. Se trata de "un vacío que era probable que fuera llenado por otras formas de identificación que podrían volverse problemáticas para el funcionamiento del sistema democrático (...) [la pospolítica es] la anunciada desaparición de las identidades colectivas y la victoria del individualismo, [sin embargo, como muy bien señala Mouffe,] la dimensión colectiva no podía ser eliminada de la política" (Mouffe, 2007, 76).

14 Afirmó Eduardo Gordon, General Director de Carabineros en el momento del conflicto con los químicos de las lacrimógenas. En Emol.cl. Gordon y uso de lacrimógenas: "No cambia la planificación" para el 21 de mayo. 20 de mayo (consultado 10 de diciembre). Disponible: http:/ / www.emol.com/noticias/ nacional / 2011 / 05 / 20 / 482767 / gordon-y-uso-de-lacrimogenas-no-cambia-laplanificacion-para-el-21-de-mayo.html

15 Cooperativa.cl. Hinzpeter autorizó utilización de bombas lacrimógenas en protestas. 20 de mayo. (consultado 1 de diciembre) Disponible: http:/ / www.cooperativa.cl/hinzpeter-autorizo-utilizacion-de-bombas-lacrimogenas-en-protestas / prontus_nots / 2011-05-20/132727.html

16 Tercera.cl Hinzpeter autoriza a carabineros uso de gas lacrimógeno a horas de marchas por 21 de mayo, 20 de mayo (consultado 11 de diciembre) Disponible: http:/ / latercera.com/ noticia / nacional / 2011 / 05 / 680-367201-9-hinzpeter-autoriza-acarabineros-uso-de-gas-lacrimogeno-a-horas-de-marchas-por.shtml 


\section{Bibliografía}

Arancibia, Juan Pablo. Comunicación Política. Fragmentos para una genealogía de la mediatización en Chile. Santiago: Editorial ARCIS, 2006.

Bourdieu, Pierre. Sobre la televisión. Barcelona: Editorial Anagrama, 2005.

Braidotti, Rosi. Sujetos nómades. Corporización y diferencia sexual en la teoría feminista contemporánea. Buenos Aires: Editorial Paidòs, 2000.

Casas, Lidia. "El aborto". En El aborto: zona de beligerancia en Chile. Olga Grau y Soledad Falabella (compiladoras). Dossier Revista Nomadias, Número 10. Santiago: Facultad de Filosofía y Humanidades de la Universidad de Chile y Editorial Cuarto Propio, 207-209, 2009.

Castillo, Alejandra. Nudos feministas. Politica, filosofía, democracia. Santiago: Editorial Palinodia, 2010.

Díaz, Jorge. “Trampas genéticas y prácticas de la visibilización. Discusiones de una imagen política del feto". Texto leído en el panel El feto que desaparece. Normatividad de la relación feto-mujer, en Segundas Jornadas Estudiantiles de Teoría de Género, Facultad de Derecho, Universidad de Chile, 2011.

Esposito, Roberto. Immunitas. Protección y negación de la vida. Buenos Aires: Amorrortu editores, 2005.

Foucault, Michel. Vigilar y castigar. El nacimiento de la prisión. Buenos Aires: Editorial Siglo Veintiuno, 2002.

-----. Historia de la sexualidad. La voluntad de saber. Buenos Aires: Editorial Siglo Veintiuno, 2000.

Haraway, Donna. Testigo_Modesto@Segundo_Milenio. HombreHembra@_Conoce_Oncoratón $\AA$. Barcelona: Editorial UOC, 2004.

Mouffe, Chantal. En torno a lo politico. Buenos Aires: Editorial Fondo de Cultura Económica, 2007.

-----. El retorno de lo político. Comunidad, ciudadanía, pluralismo, democracia radical. Barcelona: Editorial Paidòs, 1999.

Moreiras, Alberto. Línea de sombra. El no sujeto de lo politico. Santiago: Editorial Palinodia, 2006.

Rancière, Jacques. El espectador emancipado. Buenos Aires: Editorial Manantial, 2010.

Richard, Nelly. "Crítica, poderes y resistencias". En Biopoliticas del Sur. Isabel Cassigoli y Mario Sobarzo (compiladores). Colección Seminarios, Coloquios y Debates Críticos. Santiago: Editorial ARCIS, 2010.

Ronell, Avital. "Ponerse a prueba (Notas acerca de la disposición a experimentar)". En Revista Movimiento Actual, año XIV, N¹31, México, 2009.

Verón, Eliseo. El cuerpo de las imágenes. Bogotá: Editorial Norma, 2001. 